\title{
Difficult to Fold or Unfold
}

National Cancer Institute

\section{Source}

National Cancer Institute. Difficult to Fold or Unfold. NCI Thesaurus. Code C63234.

Problem associated with the use of the device in terms of the user experiencing difficulty to close or to spread out/extend length of the device, even if the operation is being performed according to labeled instructions for use. 